\title{
Condrossarcoma de escápula em felino
}

\author{
Scapula chondrosarcoma in cat \\ Ana Cristina Pacheco de Araújo1, Anderson Luís Seitz² \& David Dreimeier²
}

RESUMO

Condrossarcomas são tumores malignos em que células neoplásicas produzem uma matriz cartilaginosa, mas nunca produzem osteóide ou osso diretamente. São tumores mais comuns em cães maduros de raças de grande porte e em ovinos, sendo que os sítios de origem principais são os ossos planos do esqueleto como costelas, ossos nasais e pélve. Podem se transformar em tumores lobulados e muito grandes, apresentando um curso clínico mais prolongado, crescendo mais lentamente e desenvolvendo metástases mais tardiamente que os osteossarcomas. O objetivo desse trabalho é de relatar um caso de condrossarcoma de escápula ocorrido em um felino, fêmea, sem raça definida, de dez anos de idade, que foi atendido no Hospital de Clínicas Veterinárias da Universidade Federal do Rio Grande do Sul, Porto Alegre, Rio Grande do Sul, Brasil.

Descritores: felino, escápula, condrossarcoma.

\section{ABSTRACT}

Chondrosarcoma is a malignant tumor whose neoplasics cells produce one cartilagions matrix, but they never produce bone straight. Chondrosarcoma are tumors more common in middle aged big size breed dogs and in sheeps. The main origin places are the flat bones of the skeleton as ribs, nasal bones and pelvis. They can turn in very big tumors, presenting a longer clinical course, growing slowey and developingmetastasis more lately than osteosarcomas. The purpose of this work is to relate a case of scapula chondrosarcoma in cat, female, without breed, ten years-old, who has been examined in the Hospital de Clínicas Veterinárias (Veterinary Medical Teaching Hospital) of the Federal University of the Rio Grande do Sul, Porto Alegre, Rio Grande do Sul, Brazil.

Key words: cat, scapula, chondrosarcoma. 


\section{INTRODUÇÃO}

Os tumores apendiculares de ossos longos podem ser classificados em três categorias: tumores ósseos primários (osteossarcoma, condrossarcoma e fibrossarcoma); tumores metastáticos secundários (devido à neoplasia de glândula mamária, pulmão e próstata); invasão local a partir de tumores de tecido mole (tal como sarcoma de células). Todos são malignos e apresentam um prognóstico ruim [2,5].

Condrossarcomas são tumores malignos em que células neoplásicas produzem uma matriz cartilaginosa, mas nunca produzem osteóide ou osso diretamente [1]. Incomuns em gatos são tumores mais comuns em cães de raças grandes e em ovinos, sendo os sítios de origem principais os ossos planos do esqueleto como costelas, ossos nasais e pelve. Podem se transformar em tumores lobulados e muito grandes, tendo um curso clínico mais prolongado, crescendo mais lentamente e desenvolvendo metástases mais tardiamente que os osteossarcomas [1]. Radiologicamente o condrossarcoma poderá produzir osteólise [4]. Felizmente a espécie felina apresenta um baixo índice de metástases provenientes de tumores ósseos. Devido a isso, a amputação tem sido um método de tratamento eficaz em gatos com osteossarcoma apendicular [3].

A proposta desse trabalho é de relatar um caso de condrossarcoma de escápula ocorrido em um felino, fêmea, sem raça definida, de dez anos de idade, que foi atendido no HCV da UFRGS, Porto Alegre, Rio Grande do Sul, Brasil.

\section{RELATO DO CASO}

Felino, fêmea, sem raça definida, de dez anos de idade, apresentava claudicação e um aumento de volume no membro torácico direito de crescimento relativamente lento, cerca de seis meses. Observouse uma massa de aproximadamente 15 centímetros de diâmetro, de consistência firme, na região da escápula do membro torácico direito (MTD), podendo estar inserido ao tórax. Foram solicitados exames complementares: raio-x torácico (sem imagem aparente para metástases), do MTD (imagem compatível com neoplasia de escápula) e citologia da região (provável condrossarcoma). $\mathrm{O}$ animal foi encaminhado para cirurgia de amputação do MTD, sendo utilizado uma anestesia geral inalatória e mantendo-o no oxigênio durante todo o procedimento (Figuras 1 e 2). O MTD foi encaminhado para exame histológico, confirmando o condrossarcoma escapular (Figura 3). Após seis horas do

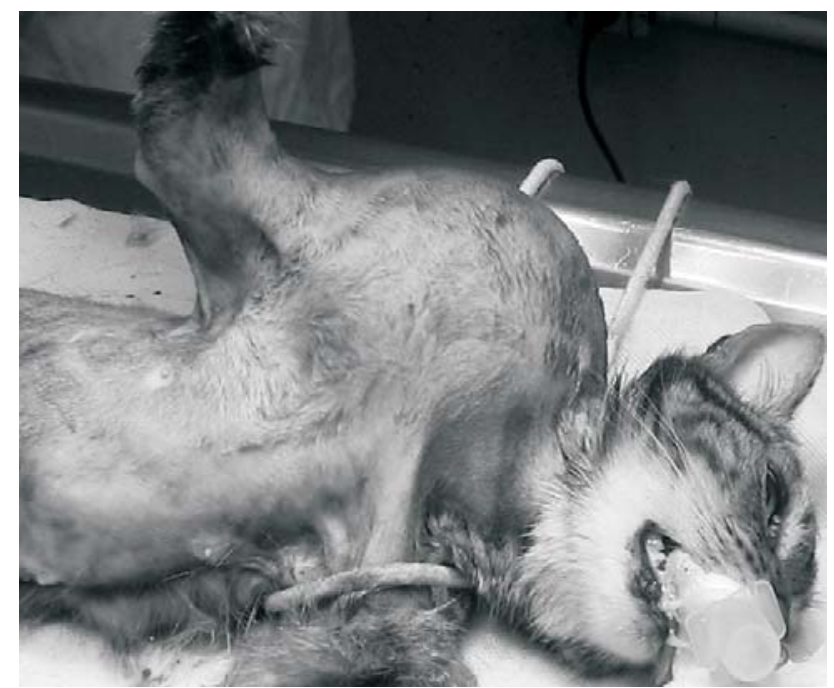

Figura 1. Felino, SRD, fêmea, 10 anos, apresentando aumento de volume na região escapular do membro torácico direito.

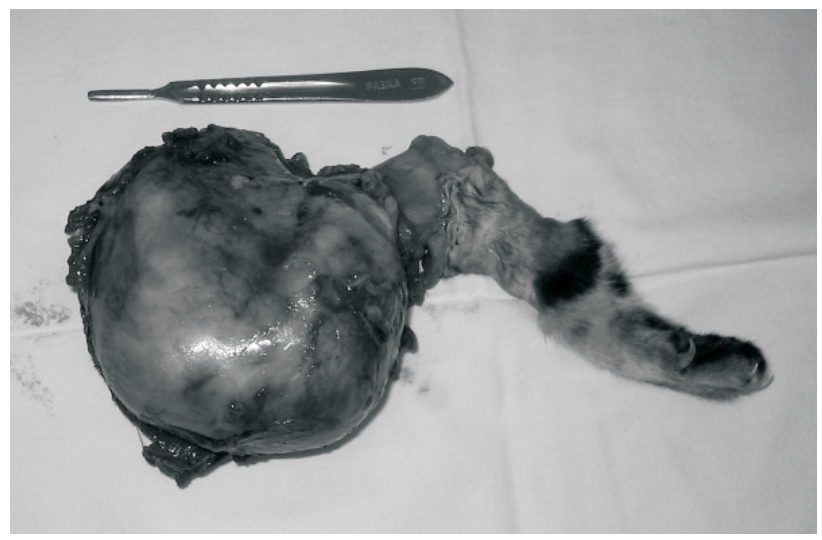

Figura 2. Membro torácico direito após amputação, evidenciando o tamanho excessivo da neoplasia.

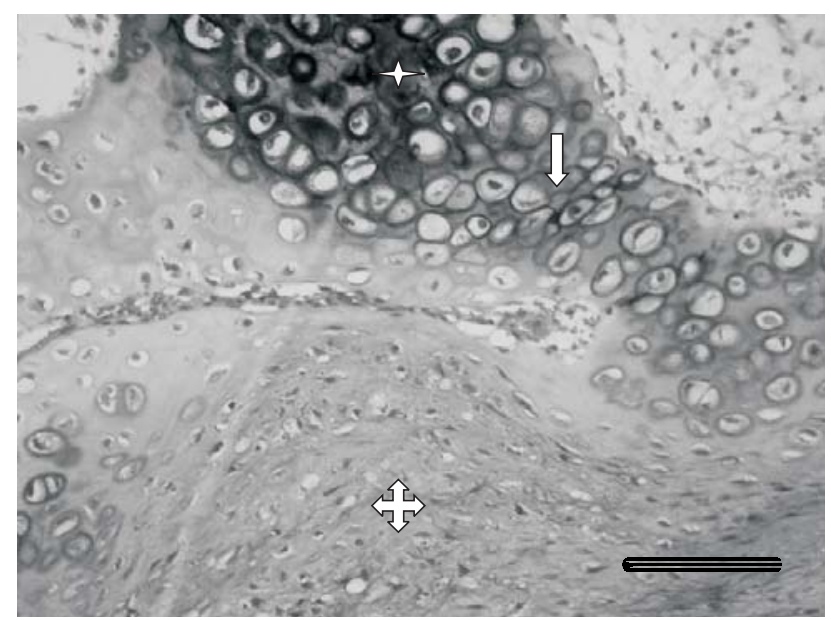

Figura 3. Ninhos com células condróides hipercromáticas (seta), com discreto pleomorfismo e ossificação endocondral (estrela). Em outras áreas ocorrem proliferação de condrócitos fusiformes com maior variação de forma e tamanho, e maior quantidade de tecido condróide (setas em cruz). Bar $5 \mathrm{~mm}$. 
procedimento cirúrgico o animal apresentou dificuldade respiratória grave e sinais de choque hipovolêmico, não sendo possível a reversão. Encaminhouse o animal para necropsia, onde foi constatado edema e congestão pulmonar severo e uma leve dilatação cardíaca, não sendo observado metástases nos demais órgãos.

\section{DISCUSSÃO}

Apesar de ser citado na literatura que os condrossarcomas apresentam uma probabilidade maior de cura que os osteossarcomas [3], e que o aparecimento de metástases é mais tardio [1], animais que apresentam neoplasias muito volumosas, que representam mais de $40 \%$ do seu peso corporal, têm uma proba- bilidade de êxito cirúrgico muito menor, pois a perda dessa massa corporal de forma abrupta pode não ser tolerada pelo organismo [5]. Antes do procedimento cirúrgico o animal pesava três quilos e após dois quilos. A amputação do membro ou do local afetado pela neoplasia ainda é um dos métodos mais eficazes de tratamento para tumores ósseos [3,4], mas a precocidade de procurar recurso tão logo seja observado o problema, tornará o prognóstico bem mais favorável. Embora muitas das abordagens estejam ainda sob pesquisa e revisão, o uso de terapia múltipla, incorporados a tratamentos inovadores, pode oferecer a melhor opção terapêutica, principalmente para animais afetados por neoplasias ósseas cujo prognóstico é extremamente desfavorável.

\section{REFERÊNCIAS}

1 Doige C.E. 1990. Sistema esquelético. In: Patologia Veterinária Especial. São Paulo: Manole, pp.558-559.

2 Kleiner J.A. \& Silva E.G. 2003. Tumores Ósseos em Pequenos Animais. Clínica Veterinária. 1: 53-65.

3 Levitt L. \& Doige C.E. 1989. Primary intraosseous fibrosarcoma in a cat. Journal of the American Veterinary Medical Association. 194: 1601-1603.

4 Newton C.D. \& Biery D.N. 1992. Moléstias Esqueléticas. In: Tratado de Medicina Interna Veterinária. v.2. São Paulo: Manole, pp.2507-2545.

5 Piermattei D.L. \& Flo G.L. 1999. Condições patológicas em animais de pequeno porte. In: Piermattei D. L. \& Flo G. L. (Eds). Manual de Fraturas dos Pequenos Animais. 3.ed. São Paulo: Manole, pp.675-676. 